\author{
Tomislav Badel ${ }^{1 \star}$, Ivana Savić Pavičín ${ }^{2}$, \\ Samir Čimićc ${ }^{1}$ and Dijana Zadravec ${ }^{3}$ \\ ${ }^{1}$ Department of Removable Prosthodontics, School of Dental \\ Medicine, University of Zagreb, Zagreb, Croatia \\ ${ }^{2}$ Department of Dental Anthropology, School of Dental \\ Medicine, University of Zagreb, Zagreb, Croatia \\ ${ }^{3}$ Department of Diagnostic and Interventional Radiology, \\ Clinical Hospital Center "Sestre milosrdnice", University of \\ Zagreb, Zagreb, Croatia \\ Dates: Received: 28 April, 2016; Accepted: 02 \\ June, 2016; Published: 03 June, 2016

\section{Mini Review \\ Diagnostics and Management of Temporomandibular Joint Disorder - A Reported Case with a Review of Literature}

*Corresponding author: Tomislav Badel, Department of Removable Prosthodontics, School of Dental Medicine, University of Zagreb, Zagreb/CROATIA, Tel: +38514802125; Fax: +38514802149; E-mail: badel@sfzg.hr

www.peertechz.com

ISSN: 2394-8418

Keywords: Temporomandibular joint; Magnetic resonance imaging; Splint; Axiography

\section{Introduction}

Orofacial pain (musculoskeletal, neuropathic, neurovascular) has a prevalence of up to $22-26 \%$ in general population, out of which $7-11 \%$ have chronic pain $[1,2]$. In clinical symptomatology which involves sounds (clicking, crepitation) in the temporomandibular joint (TMJ) and reduced mouth opening, the symptom of arthralgia (joint pain) is the most common symptom that causes patients to seek diagnosis and treatment. Prevalence of pain in the TMJ and masticatory muscles is relatively low (around 2-7\%) [3-5]. Emergency cases in oral surgery are mostly consequences of odontogenic complications and soft tissue injuries (33.94\% and $22.54 \%$ respectively), whereas TM) disorders and trigeminal neuralgia account for less than $2 \%(1.63 \%$ and $1.34 \%$ respectively) [6-8].

This review is about the clinical presentation of musculoskeletal disorders in the orofacial area. The article will emphasize medicaldental and radiological diagnostics of TMJ disorder, presented through a three-year follow-up of a reported case.

\section{Orofacial pain and temporomandibular disorders (TMDs)}

Orofacial pain has a diverse pathophysiological foundation and therefore its diagnostics and treatment include several medical and dental fields. One of the most common causes of orofacial pain, that is, pain in the area of the stomatognathic system, are TMDs. TMDs are a group of painful musculoskeletal conditions of the masticatory muscles, temporomandibular joints and adjoining structures (International Association for the Study of Pain) $[9,10]$.
The first one to research this type of orofacial pain was an otorhinolaryngologist, James B. Costen, who started describing clinical cases with heterogenic otologic symptoms in 1934 and connected them to morphological features of occlusion, such as loss of posterior teeth $[9,11]$.

The origins of the symptoms were based on only one factor - mechanical condylar displacement (Costen's syndrome), parafunction (bruxism) as a consequence of occlusal interferences causing muscular spasm and muscular hyperactivity (neuromuscular theory) and muscular hyperactivity which causes muscle tension and spasm (muscular theory). The psychological theory considers temporomandibular disorders to be psychosomatic. The hybrid theories connect a combination of certain factors - such as stressful states and occlusal relations. Today, the etiology of temporomandibular disorders is explained by the multifactorial concept, that is, by the influence of various factors (traumatic, anatomic, pathophysiological and psychosocial), as well as by the biopsychosocial concept (including the combination of biological and psychological factors, particularly in chronic temporomandibular pain) $[5,12]$.

\section{Methods}

A system of unified clinical diagnostics of TMDs has been developed and in the latest revision it was called to research criteria for temporomandibular disorders (RC/TMD). TMDs do not encompass only one diagnostic category in each individual case. It is possible to establish several diagnoses in one patient because a certain diagnostic subgroup of TMDs does not rule out another one [13]. 
Internal derangement implies changes in the disc structures or position with respect to the condyle. The most important of all intraarticular disorders is the anterior disc displacement. Clicking in the joint during mouth opening is an important sign of disc displacement with reduction. On mouth closing the disc remains anteriorly placed, which is characterized by reciprocal clicking. In patients with disc displacement without reduction, the disc is placed anteriorly in all stages of mouth opening without the possibility of repositioning into the physiological position $[7,14]$

Osteoarthritis of the TMJ includes localized active and inactive degenerative changes of cartilaginous articular surfaces and bone structures. Apart from joint pain, the main differential-diagnostic sign is clicking or crepitation during mouth opening $[15,16]$.

\section{Magnetic resonance imaging (MRI)}

The first imaging of the temporomandibular joint by magnetic resonance was in 1984. Soon, all advantages of magnetic resonance over other radiological methods were evident because the other methods were invasive and/or did not have the ability to show: the disc, bilaminar region, accompanying muscles and other soft tissues of the TMJ. Therefore, in the 1990s, MRI was the dominant method of TMJ-diagnostics $[17,18]$.

Indications of MRI are set by diagnostic criteria which were confirmed on the basis of clinical diagnosis. By use of the MRI it is possible to differentiate the complex structures of TMJs of anatomically small dimensions. Besides, by MRI, contrasts in views of soft tissues, particularly those of the disc, are clearly presented. The importance of MRI to diagnostics lies in the fact that most frequent derangements of the TMJs such as discopaties, osteoarthritis are clearly viewed. MRI is a complex and expensive diagnostic method the use of which is based upon seriously set clinical indications [19].

\section{Axiography}

Axiography is a part of instrumental functional analysis. Axiographic tracings of the mandibular movements present additional important information, which completes patient's medical history and manual functional analysis. From the obtained data the patient's individual TMJ values (curvature, sagittal condylar inclination, Bennett angle, mediotrusion and laterotrusion path) can be determined, condylar and incisal point paths during active and guided movements, and changes of condylar position due to occlusion factors can be analyzed [20]. Its advantage lies in its noninvasive recordings of condylar paths. An axiograph consists of upper and lower bows. Upper bow is, commonly, mounted similarly to the face bow. Lower bow is attached to the lower dental arch with the use of paraocclusal tray. The base of the paraocclusal tray is made of flexible metal, which enables adaptation to the lower dental arch. Adaptation of the tray can be made intraorally with various resins, or on the cast, which is better. It is made out of cold curing or light polymerizing acrylics resin (on the cast). The paraocclusal tray should not be in contact with the upper teeth (it could change movement paths and recorded values). Tray is fixed on the lower dental arch with the use of a material for temporary crowns and bridges. During the recording of mandibular movements the sensors of the lower bow transmit impulses (optoelectronic, ultrasound, magnetic, mechanical etc.), while receivers on the upper bow register them. Device's software calculates different values, depending on the device and performed movements (sagittal condylar inclination, Bennett angle, immediate side shift, etc.) [21].

Values and movement paths can be seen on the screen of the device, or on the computer. Usually, standardized movements are recorded; opening-closing, protrusion, retrusion, left and right laterotrusion. Large range of motion can be captured, depending on the device and purpose of measurement. Recording of border movements (therapeutic manipulation) can distinguish between muscular and morphological changes [22]. Any diagnostic assessment of recorded tracings is done in accordance with the medical history, and can represent important data in diagnostics and treatment of TMDs. During motion analysis, quality, quantity and symmetry can be studied. Quantity of movement can be average, hypomobile and hypermobile. Hypomobility can occur due to muscle pain, adhesions, internal derangement and inflammation of the TMJ. Hypermobility is usual with loose ligaments. Quality of movement of the healthy joint is displayed as smooth and uniform path. Symmetry is evaluated at opening-closing and protrusion movement. Healthy joints show symmetrical paths. Besides, axiographic tracings display disc displacement with reduction (exact time of displacement and reduction of the disc), gathering information for splint therapy [23]. With electronic axiography, all the data are documented on the computer, which enables comparison and monitoring of the TMDs [20].

\section{Case Report}

The presented case is of a 36-year-old female patient, who was selected from the group of patients with TMDs, consecutively collected during the period of 2001-2011; mean age 39.4 (of which $83.3 \%$ were female). All patients were examined by one specialist at the Department of Removable Prosthodontics (School of Dental Medicine, University of Zagreb). A clinical diagnosis was based on the diagnostic procedure DC/TMD Axis I [24] and on the method of manual functional analysis by Bumann and Groot Landeweer [25]. Positive findings of arthrogenic disorder indicated further radiological diagnostics; magnetic resonance imaging and computed tomography (CT). MRI served as the gold standard in the diagnosis of disc displacement, but also for displaying TMJ hard tissue. Electronic axiography was performed, as another module of diagnostics, visualizing movements of TMJ followed by expressed pathological noises.

\section{Medical history}

The patient was referred to the School of Dental Medicine, in 2008 , by recommendation of a friend, due to discomfort in the left TMJ. She first experienced stiffness of the jaw on mouth opening 15 years ago and this was accompanied by severe pain, which would subside after 10-15 minutes. Episodes of stiffness and pain continued to occur occasionally.

In 2002, she visited a specialist in oral surgery and prosthodontics. She then obtained the upper occlusal splint, which she wore only one month due to a traffic accident and health problems of her husband. 
When she tried to wear the splint again after some time, it was no longer adapted to her upper dental arch. Since then, she suffered from the aforementioned problems, but she did not seek treatment. Regarding bruxism, the patient herself noticed teeth clenching during the night, and frequent spasms of masticatory muscles at night.

\section{Mental health}

The patient informed us about her bipolar disorder, as well as about the numerous symptoms and repercussions of her social, intimate and working environment. Unrecognized and untreated postpartum depression represented, in the patient's retrospective opinion, the first sign of compromised mental health. She occasionally takes therapy (multiple medications in different periods of the recent past from the group of selective serotonin reuptake inhibitors - SSRI). Spielberger's [26] STAI (Y-form) in the form of a self-questionnaire determines anxiety as a current state (STAI 1) and as a general characteristic of a person (anxiety as a general state in the past period, STAI 2) by exceeding test standardized marginal values.

The patient did not bring accompanying medical records, but a high level of anxiety was registered. The following STAI values were determined: STAI $1=42$ and STAI $2=46$ (marginal values by age and sex for STAI $1=36.17$ and STAI $2=36.15)$.

\section{Clinical examination and diagnosis}

Manual functional analysis in 2008 revealed crepitus with pain in the left joint (diagnosis of osteoarthritis) and pain with limited opening in the right TMJ. Classification system by DC/TMD in the left TMJ showed diagnosis of osteoarthritis. During passive compression (bilaminar zone), none of the TMJs showed provoked pain, and therefore, the diagnosis of anterior disc displacement without reduction by manual functional analysis in right TMJ could not be determined with certainty [25].

The visual analogue scale (VAS: 0 , no pain; 10 most severe pain) measured the intensity of pain in the left TMJ: active opening range was $42 \mathrm{~mm}$ and the pain was VAS $=5.5$. Pain on palpation of the left TMJ was VAS $=7.5$, while the patient in rest felt minimal pain, VAS $=1.5$. Passive opening capacity accompanied also by pain in the left TMJ was $50 \mathrm{~mm}$. Also, a right laterotrusive movement caused pain in the left TMJ, although the left $(9.5 \mathrm{~mm})$ and right $(10 \mathrm{~mm})$ laterotrusion were quite symmetrical.

The patient had intact dental arches without wisdom teeth, Class I Angle, laterotrusion guided by front teeth / canines, and midlines of dental arches shifted for $1 \mathrm{~mm}$. The patient noticed wear of tooth surfaces, and the medical history confirmed bruxist activity. Intraoral inspection showed the grinding facets, mostly on the upper incisors.

\section{Radiological diagnostics}

MRI showed anterior disc displacement without reduction in the left TMJ with expressed degenerative changes (Figure 1). Computed tomography (CT) showed marked osteoarthritic changes on the left condyle; anteriorly located osteophytes with subchondral degenerative changes of the condyle and narrowed joint space of the left TMJ (Figure 2).

\section{Occlusal splint}

Although the stabilization splint is recommended for patients with osteoarthritis since it is similar to the morphology of occlusal surfaces of the dental arch on which it is located (usually the upper dental arch), the upper Michigan splint from light-curing acrylics was fabricated for the patient due to her bruxism (Figure 3). The Michigan splint has a characteristic almost flat occlusal surface, which, besides programming of masticatory muscles, positioning of the condyles in relation to the anterior position of the disc and the entire glenoid fossa, also enables smooth performance of bruxism movements

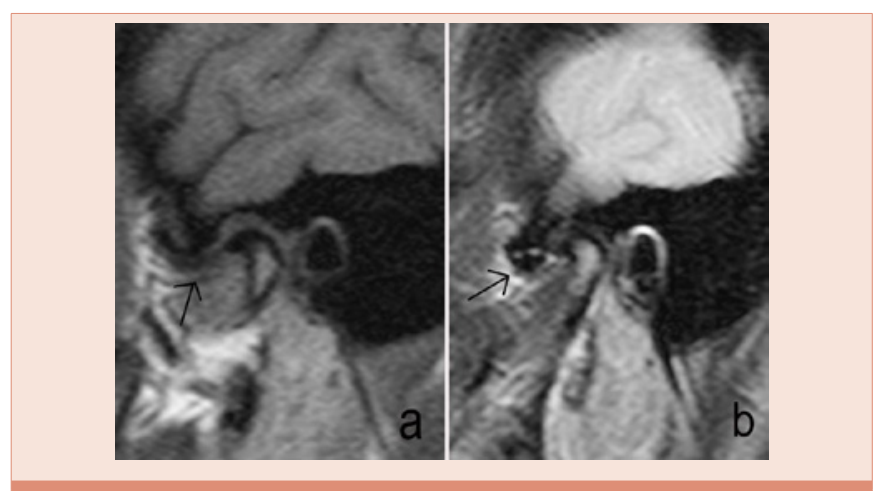

Figure 1: Magnetic resonance imaging of the anteriorly displaced disc with osteoarthritis of the left TMJ in the sagittal plane (a, T-1 weighted image; b, T2 weighted image; arrow - anterior displaced disc).

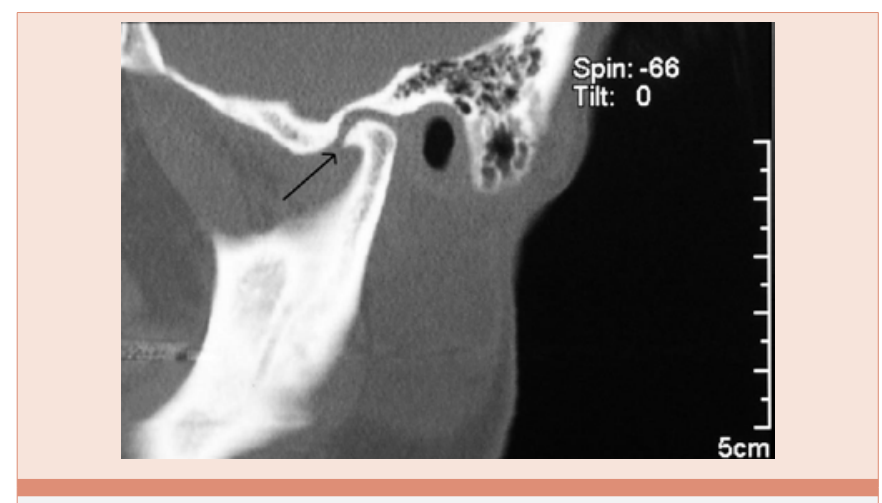

Figure 2: Computerized tomography of the left temporomandibular joint (arrow -osteophyte).

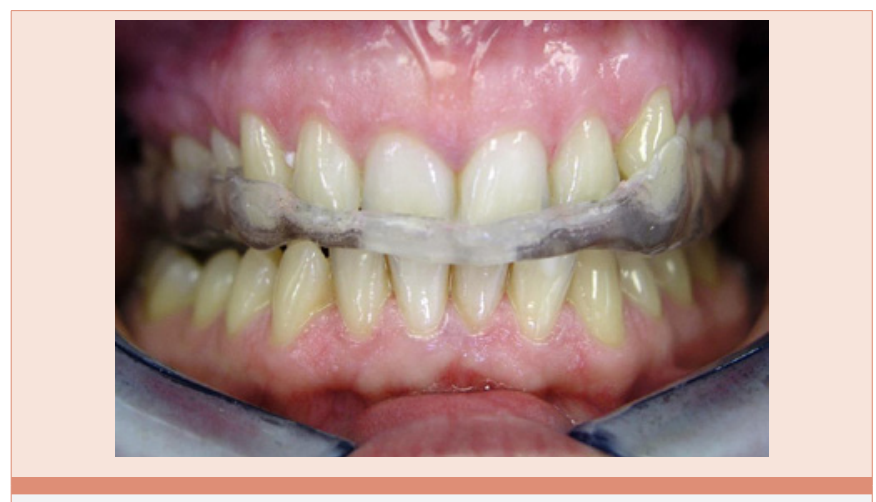

Figure 3: Michigan splint on the upper dental arch. 
[27]. The relatively flat surfaces of the occlusal splint, which are in contact with working cusps of opposing (mandibular) teeth, enable smooth adjustment of the position of the mandible within 'freedom in centric', and also protection of hard dental tissues against bruxist movements. Increasing the vertical dimension for the amount of the interocclusal free space also affects masticatory muscles relaxation.

\section{Axiography}

For the visualization of mandibular movements, particularly pathological sounds during movements, electronic axiography (Arcus Digma II, Kavo, Biberach, Germany) was performed (during the follow up in 2011). From the cast of the mandible, a paraocclusal spoon was fabricated from light cured acrylic (unitray), following the manufacturer's instructions. The paraocclusal spoon was positioned in the mouth with acrylic for temporary restoration. The manufacturer's recommendations were followed, using the kinematic axis as a posterior reference point. Clicking was confirmed in the right TMJ at $15.5 \mathrm{~mm}$ of the condyle motion on articular eminence by the 'motion analysis' module (Figure 4). The analysis also showed that the range of motion of the right condyle was $18.51 \pm 0.93 \mathrm{~mm}$, range of motion of the left condyle $18.56 \pm 0.54 \mathrm{~mm}$, right laterotrusion 13.83 \pm 0.30 , left laterotrusion $12.86 \pm 0.01$, slide between retruded contact position and intercuspal position was $2.41 \mathrm{~mm}$ in both condyles, which are all considered normal values. Analysis also showed that the condyle inclination angle was $43^{\circ}$ in right TMJ, $33.6^{\circ}$ in the left TMJ, incisal guidance $61.8^{\circ}$, right Bennett angle $9.2^{\circ}$, left Bennett angle 7.6 ${ }^{\circ}$, with no immediate side shift. These values were used for individual programming of the articulator (Protar Evo 7, Kavo, Germany) in fabrication of the second Michigan splint.

\section{Three-year follow up}

The patient wore a Michigan splint, but not regularly, and after three years (2011), a new Michigan splint for the upper dental arch was fabricated. During the follow up in 2011, active mouth opening was slightly larger $(44 \mathrm{~mm})$. Pain in the left TMJ was gone after only 6 months of therapy. Since then, there was no pain in any of the joints, while in the left there was no crepitation. Pronounced clicking in the right TMJ during the final stage of mouth opening occurred 5-6 months from the first examination, diagnosis, and wearing of splint. Current level of anxiety (follow up in 2011), STAI 1 was 56, which shows an obvious increase.

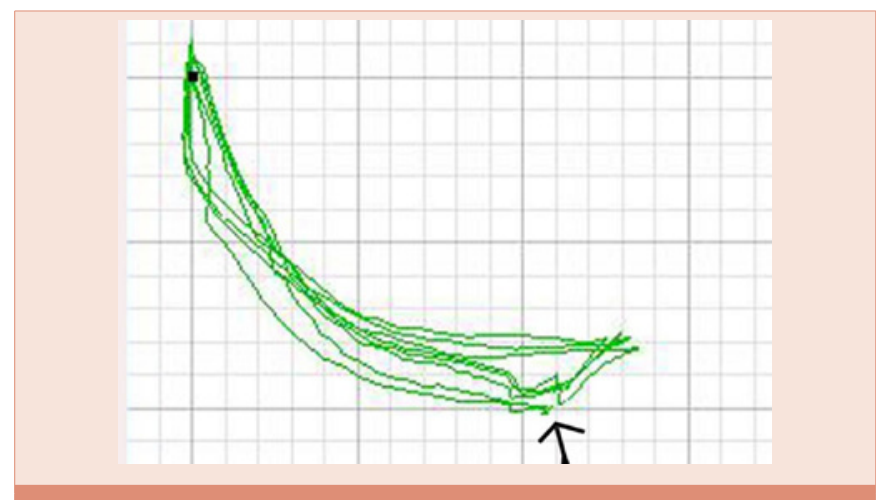

Figure 4: Clicking (arrow) in the right TMJ confirmed by 'motion analysis' module (Arcus Digma II, KaVo).

\section{Discussion}

TMDs have musculoskeletal origins because they occur as consequences of the masticatory muscles function disorder and TMJdisorder. The problematic of TMJ-disorder is multidimensional and it implies the diagnoses of disc displacement and osteoarthritis or their co-morbidity [28].

TMD symptomatology is divided into main symptoms which are, apart from the pain in masticatory muscles and/or TMJ, limited and painful mouth opening and pathological noise in the joints. In pathogenesis of the TMDs, pain is the most important symptom due to which patients seek treatment and therefore, the main goal of the treatment is pain removal. Whereas the accompanying diagnostic symptoms (nonspecific otological symptoms, tension headache) are fairly nonspecific and mostly irrelevant in TMD diagnostics, the main diagnostic symptoms can have various significance in the etiopathogenesis of individual patients [29]. In the reported case, the female patient had crepitus in the TMJ with painful and limited mouth opening.

There is no definitive agreement regarding the extent to which the osteoarthritis of TMJ is linked to the general assumption of more frequent degenerative diseases in older age, although aging is not a significant factor for the development of osteoarthritis [30,31]. TMDs are more common in working population, mainly women (proportion of female patients can be $75 \%$ and more) [32]. Malocclusion and tooth loss are also not critical for the development of osteoarthritic changes in the TMJ, as well as for TMDs in general [33].

Axiographic recordings of the TMJ motion can help with the diagnosis of muscular dyscoordination, hyper and hypomobility, dynamic asymmetries of movement, avoidance mechanisms, and joint pathologies [20,21], and therewith improve the accuracy of clinical diagnosis [22,23]. Obtained data are also used for individual setting of the articulator. Price et al. [35], studied effects of changes in articulator settings on generated occlusal tracings. Study revealed that $3 \mathrm{~mm}$ from the start of the tracing, a 5-degree change in articulator condylar inclination setting caused a $0.24 \mathrm{~mm}$ change in first molar nonworking cusp height (laterotrusion), and $0.16 \mathrm{~mm}$ change in first molar protrusive cusp height (protrusion). Since most of chair time during try-in phase for prosthodontic restorations is spend on occlusal adjustment, individual articulator setting can shorten it. For the assessment of sagittal condylar inclination, condylar and protrusional incisal path, protrusion tracings are used, while for the assessment of Bennett angle, immediate side shift, left and right tooth guidance, left and right laterotrusion movement tracings are used [36]. The case report of our female patient showed balanced capacity of condylar movements on mouth opening for both TMJs which was determined by axiography.

The most important psychological factors related to TMDs are anxiety and depression [11]. Patients with TMDs are significantly more depressed and anxious than other groups of dental patients and healthy asymptomatic subjects [37]. The DC/TMD Axis II [27], does not include anxiety measuring, but the Spielberger's STAI [26], is one easy-to-use instrument in practice as well as a screening measure. In 
general population (mean age 42.1 years) with a depressive and/or anxiety disorder who were followed for 2 years, Gerrits et al. [38], found that the most frequent pain location was headache $(76.6 \%)$, and on the contrary, the least frequent was orofacial pain (18.1\%). Joint pain was reported by $51.9 \%$ of the subjects, and it was only significant with presence of depressive and/or anxiety disorder. Pain associated with a worse course of pain can be related to depressive and anxiety disorder [39-41]. In this reported case, depression and anxiety had existed as a health issue prior to the treatment and as a co-morbidity they create difficulties in the treatment of TMDs.

Gold standard for diagnosing the TMJ disorder as well as the use of radiological diagnostics of soft intraarticular tissue is MRI. Apart from the nonspecific presentation of the TMJs on the panoramic radiograph, with respect to the clinical diagnosis of osteoarthritis, the radiological diagnostics included highly specific methods for detection of hard tissue - CT [18].

Treatment of TMD-pain complaints by occlusal splint is a generally accepted concept for a symptomatic and non-invasive treatment. There is also no definitive agreement regarding the prognosis of treatment of osteoarthritis [42-44]. In addition to that, rheumatology/physical medicine uses a broad range of physical therapies and as an additional treatment of the pain, non-steroidal anti-inflammatory drugs and complementary treatment modalities $[45,46]$.

\section{Conclusion}

Osteoarthritis is mostly responsible for joint pain in the general population. The clinical problematics of osteoarthritis of TMJ are illustrated in a case of a 36-year-old female patient. MRI is the gold standard for diagnosing the TMJ disorder as well as the use of radiological diagnostics of soft intraarticular tissue.

\section{References}

1. Benoliel R, Sharav Y (2010) Chronic orofacial pain. Curr Pain Headache Rep 14: 33-40.

2. dos Santos Calderon P, Peixoto RF, Gomes VM, da Mota Corrêa AS, de Alencar EN, et al. (2012) Concordance among different pain scales in patients with dental pain. J Orofac Pain 26: 126-131.

3. Jürgens J (2009) Sechs Leitsymptome der Kiefergelenkarthopathie. Dtsch Zahnäztl Z 64: 308-317.

4. Cooper BC, Kleinberg I (2007) Examination of a large patient population for the presence of symptoms and signs of temporomandibular disorders. Cranio 25: $114-126$

5. Jerolimov $\vee$ (2009) Temporomandibular disorders and orofacial pain. Rad 504 Medical sciences 33: 53-77.

6. Brajković B, Macan D (2002) Raščlamba hitnih slučajeva u Klinici za kirurgiju lica, čeljusti i usta KB „Dubrava“. Acta Stomatol Croat 36: 213-217.

7. Badel T, Čimić S, Munitić M, Zadravec D, Bašić Kes V, et al. (2014) Clinical view of the temporomandibular joint disorder. Acta Clin Croat 53: 462-470.

8. Badel T, Bašić Kes V, Savić Pavičin I, Zadravec D, Kern J, et al. (2012) Trigeminal neuralgia and temporomandibular joint disorder - differential diagnostics in a sample of patients with orofacial pain. Neuroepidemiology 39: 232 [abstract].

9. Türp JC (2013) Orofacial pain care in 2020: A prediction. Dtsch Zahnärztl Z 68: $600-615$
10. Okeson JP, de Leeuw R (2011) Differential diagnosis of temporomandibular disorders and other orofacial pain disorders. Dent Clin N Am 55: 105-120.

11. Emshoff R, Innerhofer K, Rudisch A, Bertram S (2002) The biological concept of "internal derangement and osteoarthrosis": a diagnostic approach in patients with temporomandibular joint pain? Oral Surg Oral Med Oral Pathol Oral Radiol Endod 93: 39-44

12. Badel T, Marotti M, Savić Pavičin I, Bašić-Kes V (2012) Temporomandibular disorders and occlusion. Acta Clin Croat 51: 419-424.

13. Schiffmanchiffman E, Ohrbach R, Truelove E, Look J, Anderson G, et al (2014) Diagnostic Criteria for Temporomandibular Disorders (DC/TMD) for Clinical and Research Applications: recommendations of the International RDC/TMD Consortium Network and Orofacial Pain Special Interest Group. J Oral Facial Pain Headache 28: 6-27.

14. Graff-Radford SB (2012) Facial pain, cervikal pain, and headache. 2012 Continuum Lifelong Learning Neurol 18: 869-882.

15. Badel T, Savić Pavičin I, Zadravec D, Krapac L, Kern J (2012) Osteoarthritic temporomandibular joint changes confirmed by magnetic resonance imaging. Reumatizam 59: 15-21.

16. Bernhardt O, Biffar R, Kocher T, Meyer G (2007) Prevalence and clinica signs of degenerative temporomandibular joint changes validated by magnetic resonance imaging in a non-patient group. Ann Anat 189: 342-346.

17. Badel T (2007) Temporomandibularni poremećaji i stomatološka protetika. Zagreb: Medicinska naklada.

18. Hunter A, Kalathingal S (2013) Diagnostic imaging for temporomandibular disorders and orofacial pain. Dent Clin N Am 57: 405-418.

19. Laškarin M, Badel T, Kern J, Savić Pavičin I, Zadravec D (2014) Metric evaluation of partially displaced temporomandibular joint disc. Acta Clin Croat 53: 310-318.

20. Čimić S, Kraljević Šimunković S, Kevilj Gospić R, Badel T, Dulčić N, et al. (2015) Movements of temporomandibular condyles during swallowing. Coll Antropol 39: 159-164.

21. Pröschel P, Morneburg T, Hugger A, Kordass B, Ottl P, et al. (2002) Articulator-related registration--a simple concept for minimizing eccentric occlusal errors in the articulator. Int J Prosthodont 15: 289-294.

22. Kraljević S, Kraljević K, Pandurić J, Ćelić R, Dulčić N (1999) Recording lower jaw movements and positions by means of electronic axiography. Acta Stomatol Croat 33: 155-164

23. Kobs G, Bernhardt O, Meyer G (2004) Accuracy of computerized axiography controlled by MRI in detecting internal derangements of the TMJ. Stomatol Baltic Dent Maxillofac J 6: 7-10.

24. Türp JC (2014) Diagnostic criteria for temporomandibular disorders (DC/ TMD) - Presentation of the Axis I classification. J Craniomandib Funct 6: 213-219.

25. Bumann A, Lotzman U (2002) TMJ Disorders and Orofacial Pain - The Role of Dentistry in a Multidisciplinary Diagnostic Approach. Thieme, Stuttgart New York.

26. Spielberger CD (2001) Priručnik za upitnik anksioznosti kao stanja i osobine ličnosti STAI [Croatian edition]. Jastrebarsko: Slap.

27. Badel T, Simonić-Kocijan S, Lajnert V, Dulčić N, Zadravec D (2013) Michigan splint and treatment of temporomandibular joint - review of literature. Medicina fluminensis 49: 112-120.

28. Park JW, Song HH, Roh HS, Kim YK, Lee JY (2012) Correlation between clinical diagnosis based on RDC/TMD and MRI findings of TMJ internal derangement. Int J Oral Maxillofac Surg 41: 103-108.

29. Badel T, Pandurić J, Marotti M, Kocijan Lovko S (2006) Temporomandibular joint disorder in an otalgia patient. Acta Stomatol Croat 40: 175-181.

30. Zhao YP, Zhang ZY, Wu YT, Zhang WL, Ma XC (2011) Investigation of the clinical and radiographic features of osteoarthrosis of the temporomandibular 
joints in adolescents and young adults. Oral Surg Oral Med Oral Pathol Oral Radiol Endod. 111: e27-34.

31. Machon V, Hirjak D, Lukas J (2011) Therapy of the osteoarthritis of the temporomandibular joint. J Craniomaxillofac Surg 39: 127-130.

32. Guarda-Nardini L, Piccotti F, Mogno G, Favero L, Manfredini D (2012) Agerelated differences in temporomandibular disorder diagnoses. Cranio 30 : 103-109

33. Manfredini D, Piccotti F, Ferronato G, Guarda-Nardini L (2010) Age peaks of different RDC/TMD diagnoses in a patient population. J Dent 38: 392-399.

34. Ćimić S, Šimunković SK, Badel T, Dulčić N, Alajbeg I, et al. (2014) Measurements of the sagittal condylar inclination: intraindividual variations. Cranio. 32: 104-109.

35. Price RB, Kolling JN, Clayton JA (1991) Effects of changes in articulator settings on generated occlusal tracings. Part I: Condylar inclination and progressive side shift settings. J Prosthet Dent 65: 237-243.

36. Čimić S, Kraljević Šimunković S, Simonić Kocijan S, Matijević J, Dulčić N et al. (2015) Articulator-related registration and analysis of sagittal condylar inclination. Acta Clin Croat 54: 432-437.

37. Dworkin SF (2006) Psychological and Psychosocial Assessment. In Laskin DM, Green CS, Hylander WL (eds) Temporomandibular disorders. An Evidence-Based Approach to Diagnosis and Treatment. Quintessence, Chicago p 203-217.

38. Gerrits MM, Vogelzangs N, van Oppen $\mathrm{P}$, van Marwijk HW, van der Horst $\mathrm{H}$ et al. (2012) Impact of pain on the course of depressive and anxiety disorders. Pain. 153: 429-436.
39. Dougall AL, Jimenez CA, Haggard RA, Stowell AW, Riggs RR, et al. (2012) Biopsychosocial factors associated with the subcategories of acute temporomandibular joint disorders. J Orofac Pain 26: 7-16.

40. Puretić MB, Demarin V (2012) Neuroplasticity mechanisms in the pathophysiology of chronic pain. Acta Clin Croat 51: 425-429.

41. Giannakopoulos NN, Keller L, Rammelsberg P, Kronmüller KT, Schmitter M (2010) Anxiety and depression in patients with chronic temporomandibular pain and in controls. J Dent 38: 369-376.

42. Greene CS (2006) Concepts of TMD Etiology: Effects on Diagnostics and Treatment. In: Laskin DM, Green CS, Hylander WL (eds) Temporomandibular Disorders. An Evidence-Based Approach to Diagnosis and Treatment. Quintessence, Chicago p 219-228.

43. Simmons HC $3^{\text {rd }}$ (2012) A critical review of Dr. Charles S. Greene's article titled "Managing the Care of Patients with Temporomandibular Disorders: a new Guideline for Care" and a revision of the American Association for Dental Research's 1996 policy statement on temporomandibular disorders, approved by the AADR Council in March 2010, J Am Dent Assoc 141: 10861088.

44. Rollman A, Visscher CM, Gorter RC, Naeije M (2013) Improvement in patients with a TMD-pain report. A 6-month follow-up study. J Oral Rehabil 40: 5-14.

45. Badel T, Jerolimov V, Marotti M, Krolo I (2012) Stabilization splint treatment on complete denture - two reported cases. Eur J Prosthodont Restor Dent 20: $17-21$.

46. Grazio S, Balen D (2011) Complementary and alternative treatment of musculoskeletal pain. Acta Clin Croat 50: 513-530. 